\title{
Prevalence and Associated Factors of Hypertension: A Community-Based Cross-Sectional Study in Municipalities of Kathmandu, Nepal
}

\author{
Raja Ram Dhungana, ${ }^{1}$ Achyut Raj Pandey, ${ }^{2}$ Bihungum Bista, ${ }^{2}$ \\ Suira Joshi, ${ }^{3}$ and Surya Devkota ${ }^{4}$ \\ ${ }^{1}$ Nepal Family Development Foundation, Kathmandu, Nepal \\ ${ }^{2}$ Nepal Health Research Council, Kathmandu, Nepal \\ ${ }^{3}$ Ministry of Health and Population, Kathmandu, Nepal \\ ${ }^{4}$ Manmohan Cardiothoracic, Vascular and Transplant Centre, Institute of Medicine, Tribhuvan University, Kathmandu, Nepal \\ Correspondence should be addressed to Raja Ram Dhungana; raja.dhungana@gmail.com
}

Received 22 March 2016; Accepted 24 April 2016

Academic Editor: Roberto Pontremoli

Copyright (C) 2016 Raja Ram Dhungana et al. This is an open access article distributed under the Creative Commons Attribution License, which permits unrestricted use, distribution, and reproduction in any medium, provided the original work is properly cited.

Objective. This study aimed to assess the prevalence and associated factors of hypertension in newly declared municipalities of Kathmandu, Nepal. Design, Settings, and Participants. This was a community-based cross-sectional study conducted in the municipalities of Kathmandu District, Nepal, between January and July 2015. Study participants were aged 18 to 70 years, residing permanently in the study sites. Municipalities, Wards, households, and respondents were selected randomly. Results. Of the 587 participants, $58.8 \%$ were females, mean (SD) age was 42.3 (13.5) years, $29.3 \%$ had no formal education, $35.1 \%$ were Brahmins, and 41.2\% were homemakers. Prevalence of hypertension was 32.5\% (95\% CI: 28.7-36.3). Age, gender, education, ethnicity, occupation, smoking, alcohol consumption, physical activity, diabetes, menopausal history, and family history of cardiovascular disease (CVD) and hypertension were significantly associated with hypertension. In multivariable analysis, smoking, alcohol consumption, physical activity, body mass index, and diabetes were identified as significant explanatory variables for hypertension. Conclusion. This study demonstrated that the people living in newly established municipalities of Kathmandu, Nepal, have a high burden of hypertension as well as its associated factors. Therefore, community-based preventive approaches like lifestyle modification and early detection and treatment of hypertension might bring a substantial change in tackling the burden effectively.

\section{Background}

Worldwide levels of hypertension represent the global public health crisis. Hypertension affects around $22 \%$ of people aged 18 years and over and is responsible for an estimated 9.4 million deaths per year globally $[1,2]$. Raised blood pressure mostly remains asymptomatic while increasing the risk of heart disease, stroke, and renal failure [3]. It contributes to at least $45 \%$ of deaths due to heart disease and $51 \%$ of deaths as a result of stroke [1]. Additionally, around $10 \%$ of healthcare expenditure is directly related to hypertension and its complications [3].
The increasing prevalence of hypertension in developing countries is a major concern. According to recent estimates from the World Health Organization, two-thirds of hypertensive people live in developing countries [4]. Africa has the highest prevalence of hypertension (29.6\%) followed by the Eastern Mediterranean (26.9\%), South East Asia (24.7\%), Europe (23.3\%), the Western Pacific (18.7\%), and America (18.2\%) [2]. Among South Asian countries, Nepal reported the second highest proportion of hypertensive people (27.3\%) after Afghanistan (29\%) [2].

There are a range of factors that increase the risk of developing hypertension [5]. Tobacco use increases the 
incidence of cardiovascular diseases including hypertension [6]. Alcohol consumption is related to $5 \%$ to $30 \%$ of hypertension cases in the general population $[7,8]$. Similarly, about $30 \%$ of cases are attributed to increased salt consumption and $20 \%$ to physical inactivity [9]. Hypertension has also well-established relationship with obesity and diabetes [10, 11]. Recent reports have provided evidence that increasing rates of noncommunicable diseases, including hypertension, are associated with other determinants like increases in rapid unplanned urbanization, globalization, and sociodemographic and nutritional transition $[12,13]$.

The surroundings of Kathmandu metropolitan city have many of the characteristics that can lead to an increase in noncommunicable diseases or conditions like hypertension. These factors include high internal migration from other regions of Nepal, increasing sedentary lifestyles, inadequate development and planning, high levels of air pollution, and changes in the dietary habits of residents [14]. However, there is little evidence on the prevalence and risk factors of hypertension in the periurban areas of Kathmandu District. Therefore, this study was conducted to estimate the prevalence of hypertension and to quantify health and social determinants related to hypertension in periurban areas of Kathmandu.

\section{Methods}

2.1. Study Design, Settings, and Participants. This was a community-based, cross-sectional study conducted in the newly established (established in December 2014) municipalities of Kathmandu District, Nepal, between January and July 2015. The ten municipalities are located on the outskirts of Kathmandu metropolitan city and are areas with rapid, unplanned urbanization and with high immigration of people from other areas of Nepal [14]. These municipalities contain a total population of more than 300,000 people [15].

Study participants were aged between 18 and 70 years, holding permanent resident status in the study areas at the time of study. Individuals diagnosed with any mental disorder or pregnant women were excluded from the study.

Of the ten municipalities in Kathmandu, two municipalities were randomly selected, one each from the eastern (Kageshwari-Manohara) and western (Nagarjun) clusters. These municipalities consist of around 130,000 people living in 27 Wards. From the total Wards, four Wards, two from each municipality, were randomly selected. The sample was proportionately allocated to each Ward based on the number of households in the Ward. A systematic random sampling method was then applied to choose 600 households from around 5600 households. The study area was mapped and each household was assigned a number, beginning from clockwise direction from first lane of eastern corner of the sites. One household was randomly selected from the first 10 houses using random number table, and then every 10th household from that initial household was approached systematically until the sample size was completed. Among adult members of each household, one individual from that household was enrolled in the study by KISH method [16].
2.2. Data Collection. Data were collected by face-to-face interview, anthropometric measurements, and clinical examinations. Fifteen medical professionals were recruited and trained in data collection methods.

2.2.1. Interview. The survey questionnaire (WHO STEPwise questionnaires) covered the demographics and health behaviors of respondents [17]. Demographic information included age, sex, ethnicity, marital status, years at school, and primary occupation. The health behaviors included tobacco use, alcohol consumption, fruit and vegetable consumption, and physical activity.

Tobacco Use. Questions were asked to identify current users, daily users, and past users.

Alcohol Consumption. Questions were asked to determine the current users of alcohol. Detailed information, such as the number of standard drinks consumed in the last 30 days, was obtained from current users. Pictorial cards showing different kinds of glasses and bowls most commonly used in Nepal were used to help the participants recall the amount of alcohol consumed. The amount, as identified by the respondent, was then used to estimate the number of standard drinks of alcohol consumed (one standard drink being defined as 10 grams of ethanol).

Diet. Seventy-two hours dietary recall was used to estimate fruit and vegetable consumption. Determination of the amount of fruit and vegetables consumed was aided by pictorial show cards and standard measuring cups.

Physical Activity. Seven-day history of physical activity was recorded. The physical activities related to work, transport, and recreational activities were categorized into vigorous, moderate, and low levels of activity in accordance with published guidelines $[18,19]$. Vigorous physical activity was defined as any activity that had more than six Metabolic Equivalent of Task (MET) values. Moderate physical activity was defined as any activity that had MET values between three and six [18]. Physical activity having less than three METs, like spending time sitting at a desk or travelling in a car, bus, or train, was considered low or sedentary physical activity.

Diabetes. Participants were requested to provide information on status of diabetes or diabetic medication history.

2.2.2. Anthropometric Measurement. Height and weight were measured using the digital weighing machines and the portable standard stature scales, respectively, from which body mass index (BMI) was calculated. Waist and hip circumferences were also measured by Johnson's nonstretchable measuring tape in order to determine the waist-hip ratio.

2.2.3. Clinical Examination. Trained data collectors measured blood pressure using an aneroid sphygmomanometer. Before taking the measurements, respondents were requested 
to sit quietly and rest for 15 minutes with legs uncrossed. Three readings of the systolic and diastolic blood pressure were taken with three-minute rest between each reading and the mean of second and third reading was used for analysis.

2.2.4. Operational Definitions. Standard operational definitions were adopted for key variables to maintain consistency and uniformity of the information.

Poor. Poor was defined as those having income less than 40,933 Nepalese Rupees per annum [20].

Current Smoker. Current smokers were defined as those who reported smoking any tobacco product within last 30 days. Respondents who reported smoking at least 100 cigarettes in their lifetime and who, at the time of the survey, did not smoke were defined as past smoker [21].

Current Alcohol Drinkers. Those who consumed alcohol within last 30 days were considered current alcohol drinkers [21].

Sufficient Fruit and Vegetables Intake. Intake of at least $400 \mathrm{gm}$ of fruit and vegetables in a day was regarded as sufficient [22].

Sufficient Physical Activity. Sufficient physical activity was defined as $\geq 600 \mathrm{MET}$ s of moderate and vigorous activity in a week [18].

Hypertension. The diagnostic criterion for hypertension was set as a systolic blood pressure $\geq 140 \mathrm{mmHg}$ and/or a diastolic blood pressure $\geq 90 \mathrm{mmHg}$ as recommended by Joint National Committee-VII. Those research participants who were using antihypertensive medicine were also considered as hypertensive [23].

Diabetes. Self-reported status or the use of any antidiabetic medication was the diagnostic criteria for diabetes.

2.3. Sample Size. Sample size was calculated for a single sample of the estimated population using the specified absolute precision formula $(N=z 2 p q / d 2)$ [24]. For estimation of sample size, prevalence of hypertension was taken as $25.7 \%$ [25] with 5\% of allowable error. The sample size was adjusted with design effect (multiplied by 2) and nonresponse rate (2\%). The total calculated sample size was 600 .

2.4. Data Management and Analysis. Data were compiled, edited, and checked to maintain consistency. Duplications and omissions of data were corrected before coding and entering them in Epidata V.2.1. Data were then exported to SPSS V.16.0 for analysis.

Frequencies and percentages were calculated to identify the distribution of sociodemographic characteristics. Chi-square and independent $t$-tests were conducted for comparing proportions of categorical and mean of continuous variables. Nonnormally distributed data were analyzed by Mann-Whitney $U$ test. For multivariable analysis, hypertension was considered as a dichotomous dependent variable. Study variables having significant association with hypertension in bivariate analysis were entered in logistic model using Stepwise Forward Conditional method. The result was validated using Backward Conditional method. Variables having collinearity and confounding effects (waist circumference and hip circumference with BMI; age with diabetes) were excluded from the analysis. All tests were twotailed and $p<0.05$ was considered statistically significant.

\section{Results}

3.1. Sociodemographic Characteristics. The total number of study participants was 587, excluding 13 who did not respond well. Of these, $58.8 \%$ were females. The mean (SD) age of participants was 42.3 (13.5) years. Nearly one-third (29.3\%) of participants had no formal education. Of total participants, Brahmins comprised the largest proportion (35.1\%), followed by Chetris $(29.1 \%)$ and Newars $(20.3 \%)$. Nearly half of the respondents were homemakers $(41.2 \%)$ and were living below the poverty line (49\%).

The difference in male and female count was not statistically significant by age group, ethnicity, and income level. However, education level and occupation significantly varied by gender (Table 1).

3.2. Prevalence of Hypertension. The prevalence of hypertension in the study population was $32.5 \%$ (95\% CI: $28.7-$ 36.3). However, only $15.8 \%$ of participants were taking antihypertensive medication. Half of them (53.8\% of hypertensive participants on treatment) were taking calcium channel blocker. A small proportion of the participants $(2.2 \%$ of hypertensive participants on treatment) were also taking ayurvedic medicine for controlling hypertension. Of those on treatment, only half had controlled hypertension $(<140 / 90 \mathrm{mmHg})$.

3.3. Sociodemographic Characteristics and Hypertension. More males than females had high blood pressure (Table 2). Hypertension was also associated with age. Participants with lower educational status (primary and lower) were more likely to have hypertension. Ethnicity was also significantly associated with hypertension. However, there was no statistically significant association between occupation and hypertension.

\subsection{Factors Associated with Hypertension}

3.4.1. Smoking. The proportion of current and past smokers was $19.9 \%$ and $17 \%$, respectively. Both current smoking $(p=0.009)$ and past smoking $(p=0.001)$ participants were significantly associated with hypertension. The mean duration of smoking was also significantly higher $(p=$ 0.012) in hypertensive participants than in normotensive participants (Table 3). 
TABLE 1: Distribution of sociodemographic characteristics by gender.

\begin{tabular}{|c|c|c|c|c|c|}
\hline Variables & Categories & $\begin{array}{c}\text { Male } \\
N(\%)\end{array}$ & $\begin{array}{c}\text { Female } \\
N(\%)\end{array}$ & $\begin{array}{c}\text { Total } \\
N(\%)\end{array}$ & $p$ value \\
\hline \multirow{5}{*}{ Age groups } & $<30$ years & $49(20.2)$ & $69(20.0)$ & $118(20.1)$ & \multirow{5}{*}{0.147} \\
\hline & $30-39$ years & $47(19.4)$ & $90(26.1)$ & $137(23.3)$ & \\
\hline & $40-49$ years & $69(28.5)$ & $81(23.5)$ & $150(25.6)$ & \\
\hline & $50-59$ years & $37(15.3)$ & $63(18.3)$ & $100(17.0)$ & \\
\hline & $>60$ years & $40(16.5)$ & $42(12.2)$ & $82(14.0)$ & \\
\hline \multirow{5}{*}{ Education } & No formal education & $29(12.0)$ & $143(41.4)$ & $172(29.3)$ & \multirow{5}{*}{$<0.01$} \\
\hline & Primary and lower & $30(12.4)$ & $53(15.4)$ & $83(14.1)$ & \\
\hline & Secondary & $64(26.4)$ & $65(18.8)$ & $129(22.0)$ & \\
\hline & Higher Secondary & $52(21.5)$ & $47(13.6)$ & 99 (16.9) & \\
\hline & Bachelor and higher & $67(27.7)$ & $37(10.7)$ & $104(17.7)$ & \\
\hline \multirow{4}{*}{ Ethnicity } & Brahman & $95(39.3)$ & $111(32.2)$ & $206(35.1)$ & \multirow{4}{*}{0.246} \\
\hline & Chetri & $68(28.1)$ & $103(29.9)$ & $171(29.1)$ & \\
\hline & Newar & $48(19.8)$ & $71(20.6)$ & $119(20.3)$ & \\
\hline & Others & $31(12.8)$ & $60(17.4)$ & $91(15.5)$ & \\
\hline \multirow{4}{*}{ Occupation } & Job & $66(27.3)$ & $35(10.1)$ & $101(17.2)$ & \multirow{4}{*}{$<0.01$} \\
\hline & Self-employed & $87(36.0)$ & $54(15.7)$ & $141(24.0)$ & \\
\hline & Homemaker & $30(12.4)$ & $212(61.4)$ & $242(41.2)$ & \\
\hline & Others & $59(24.4)$ & $44(12.8)$ & $103(17.5)$ & \\
\hline \multirow{3}{*}{ Marital status } & Unmarried & $36(14.9)$ & $32(9.3)$ & $68(11.6)$ & \multirow{3}{*}{$<0.01$} \\
\hline & Married & $204(84.3)$ & $283(82.0)$ & $487(83)$ & \\
\hline & Others (separated or widow) & $2(0.8)$ & $30(8.7)$ & $32(5.5)$ & \\
\hline \multirow{2}{*}{ Socioeconomic status } & Below poverty line & $115(47.9)$ & $170(49.7)$ & $285(49.0)$ & \multirow{2}{*}{0.671} \\
\hline & Above poverty line & $125(52.1)$ & $172(50.3)$ & $297(51.0)$ & \\
\hline
\end{tabular}

Note: primary and lower education, grade 1-5; secondary, grade 6-10; higher secondary, grade 11-12; job, governmental or nongovernmental employment; selfemployed, working for oneself as a freelancer or the owner of a business or working in own farm; homemaker, a person, especially a housewife, who manages a home; other occupations, volunteer or student or unemployed or retired; below poverty line, income less than 40,933 Nepalese Rupees per annum.

3.4.2. Alcohol Consumption. More than one-quarter (27\%) of participants reported current alcohol use. Alcohol consumption had a significant positive association $(p=0.035)$ with hypertension. The hypertensive participants reported drinking a significantly higher number of standard drinks in a single sitting $(p<0.001)$ than normotensive participants (Table 3).

3.4.3. Fruit and Vegetable Consumption. Approximately, 1 in every 10 participants (11.4\%) reported consuming the recommended amount of fruit and vegetable daily. The daily median intake for total fruit and vegetables per person was $188.9 \mathrm{gm}$ (interquartile range (IQR): $204 \mathrm{gm}$ ). For green leafy vegetable, only the median intake was $75 \mathrm{gm}$ per day (IQR: $125 \mathrm{gm})$. Median daily fruit intake per person was $45 \mathrm{gm}$ (IQR: $120 \mathrm{gm}$ ). Fruit and vegetable intake was not significantly associated $(p=0.542)$ with hypertension.

3.4.4. Physical Activity. More than three-quarters of participants $(78.4 \%)$ had the sufficient physical activity level ( $\geq 600 \mathrm{METs} /$ week). The median (IQR) of METs of moderate and vigorous physical activities per week was 1850 (IQR: 2853). Adequate physical activity was associated with normal blood pressure $(p=0.038)$.
3.4.5. Obesity. The mean of body mass index (BMI) among respondents was $24.8 \mathrm{~kg} / \mathrm{m}^{2}$. It was significantly different $(p<0.001)$ between people having high and normal blood pressure. Similarly, waist $(p<0.001)$ and hip $(p<0.004)$ circumferences were also significantly higher in hypertensive participants than in normotensive participants.

3.4.6. Diabetes and Other Factors. One in every ten participants $(10.7 \%)$ reported that they had diabetes mellitus. Similarly, $12.6 \%$ of participants had the presence of cardiovascular disease (CVD) among their first-degree relatives and $31.6 \%$ of female participants had menopausal history. Diabetes $(p<0.001)$, cessation of menstruation $(p<$ $0.001)$, and having family history of CVD $(p<0.001)$ were significantly associated with hypertension (Table 3 ).

3.5. Adjusted Associated Factors of Hypertension. In multivariable model, BMI $(\beta=0.127$ and $p<0.001)$, smoking $(\beta=0.671$ and $p=0.005)$, alcohol use $(\beta=0.473$ and $p=0.03)$, insufficient physical activity $(\beta=0.472$ and $p=0.04)$, and presence of diabetes $(\beta=0.934$ and $p=$ 0.001 ) were identified as significant factors associated with hypertension (Table 4). Every unit gain in BMI increased the likelihood of having hypertension by $13.5 \%$. The chance of 
TABLE 2: Association of sociodemographic characteristics with hypertension.

\begin{tabular}{|c|c|c|c|c|}
\hline \multirow{3}{*}{ Variables } & \multirow{3}{*}{ Categories } & \multicolumn{2}{|c|}{ Hypertension } & \multirow{3}{*}{$p$ value } \\
\hline & & Yes & No & \\
\hline & & $N(\%)$ & $N(\%)$ & \\
\hline \multirow{2}{*}{ Gender } & Male & $93(38.4)$ & $149(61.6)$ & \multirow{2}{*}{0.011} \\
\hline & Female & $98(28.4)$ & $247(71.6)$ & \\
\hline \multirow{5}{*}{ Age groups } & $<30$ years & $7(5.9)$ & $111(94.1)$ & \multirow{5}{*}{$<0.001$} \\
\hline & $30-39$ years & $22(16.1)$ & $115(83.9)$ & \\
\hline & $40-49$ years & $71(47.3)$ & $79(52.7)$ & \\
\hline & $50-59$ years & $45(45.0)$ & $55(55.0)$ & \\
\hline & $\geq 60$ years & $46(56.1)$ & $36(43.9)$ & \\
\hline \multirow{5}{*}{ Education } & No formal education & $72(41.9)$ & $100(58.1)$ & \multirow{5}{*}{$<0.01$} \\
\hline & Primary and lower & $33(39.8)$ & $50(60.2)$ & \\
\hline & Secondary & $37(28.7)$ & $92(71.3)$ & \\
\hline & Higher secondary & $22(22.2)$ & $77(77.8)$ & \\
\hline & Bachelor and higher & $27(26.0)$ & $77(74.0)$ & \\
\hline \multirow{4}{*}{ Ethnicity } & Brahman & $54(26.2)$ & $152(73.8)$ & \multirow{4}{*}{0.049} \\
\hline & Chetri & $55(32.2)$ & $116(67.8)$ & \\
\hline & Newar & $46(38.7)$ & $73(61.3)$ & \\
\hline & Other & $36(50.0)$ & $3(50.0)$ & \\
\hline \multirow{4}{*}{ Occupation } & Job & $32(31.7)$ & $69(68.3)$ & \multirow{4}{*}{0.725} \\
\hline & Self-employed & $43(30.5)$ & $98(69.5)$ & \\
\hline & Homemaker & $85(35.1)$ & $157(64.9)$ & \\
\hline & Others & $31(30.1)$ & $72(69.9)$ & \\
\hline \multirow{3}{*}{ Marital status } & Unmarried & $8(11.8)$ & $60(88.2)$ & \multirow{3}{*}{$<0.001$} \\
\hline & Married & $167(34.3)$ & $320(65.7)$ & \\
\hline & Others (separated or widow) & $16(50.0)$ & $16(50.0)$ & \\
\hline \multirow{2}{*}{ Socioeconomic status } & Below poverty line & $95(33.3)$ & $190(66.7)$ & \multirow{2}{*}{0.665} \\
\hline & Above poverty line & $94(31.6)$ & $203(68.4)$ & \\
\hline
\end{tabular}

Note: primary and lower education, grade 1-5; secondary, grade 6-10; higher secondary, grade 11-12; job, governmental or nongovernmental employment; selfemployed, working for oneself as a freelancer or the owner of a business or working in own farm; homemaker, a person, especially a housewife, who manages a home; other occupation, volunteer or student or unemployed or retired; below poverty line, income less than 40,933 Nepalese Rupees per annum.

being hypertensive among current smokers was 1.95 times higher than among nonsmokers. Similarly, current alcohol users had $60 \%$ higher chance of having hypertension than the participants who refrained from alcohol. After controlling for other factors, the odds of being hypertensive were about $60 \%$ higher for the participants who had insufficient physical activity compared to those who had sufficient physical activity. In the same way, presence of diabetes among study participants increased the odds of being hypertensive by 2.54 times compared to nondiabetic participants.

\section{Discussion}

Our study found a high prevalence of hypertension in people living in the newly declared municipalities of Kathmandu. The factors associated with hypertension in this study group were found to be smoking, BMI, alcohol use, poor physical activity, and diabetes. This was the first community-based study conducted to estimate the prevalence of hypertension and identify its associated factors in the area. However, this study could not examine causal relationship between hypertension and its risk factors because of the nature of study design.

The prevalence of hypertension in the study population (32.5\%) was higher than in those of noncommunicable disease (NCD) risk factor surveys in Nepal (21.5\% in 2007; $25.7 \%$ in 2013) [21, 25]. This disparity in findings may be due to differences in the study populations as the NCD surveys were conducted both in urban and in rural areas, while the current study was conducted in a periurban setting. Rural Nepal has a lower burden of hypertension than urban areas [26]. Similarly, the finding was nearly the double of the hypertension prevalence $(19.7 \%)$ reported by a study conducted in similar setting of Kathmandu in 2005 [27]. This almost twofold increase in hypertension prevalence in ten years may be due to changes in living conditions and lifestyle in that time. This is further supported by the findings from a study conducted in rural areas of Kathmandu that reported a threefold increase in hypertension prevalence in 25 years [26]. This increase was attributed to increasing BMI in the study population [28].

Although it is well established that smoking increases the risk of hypertension, the strength of this association may 
TABLE 3: Association of behavioral, metabolic, and other factors with hypertension.

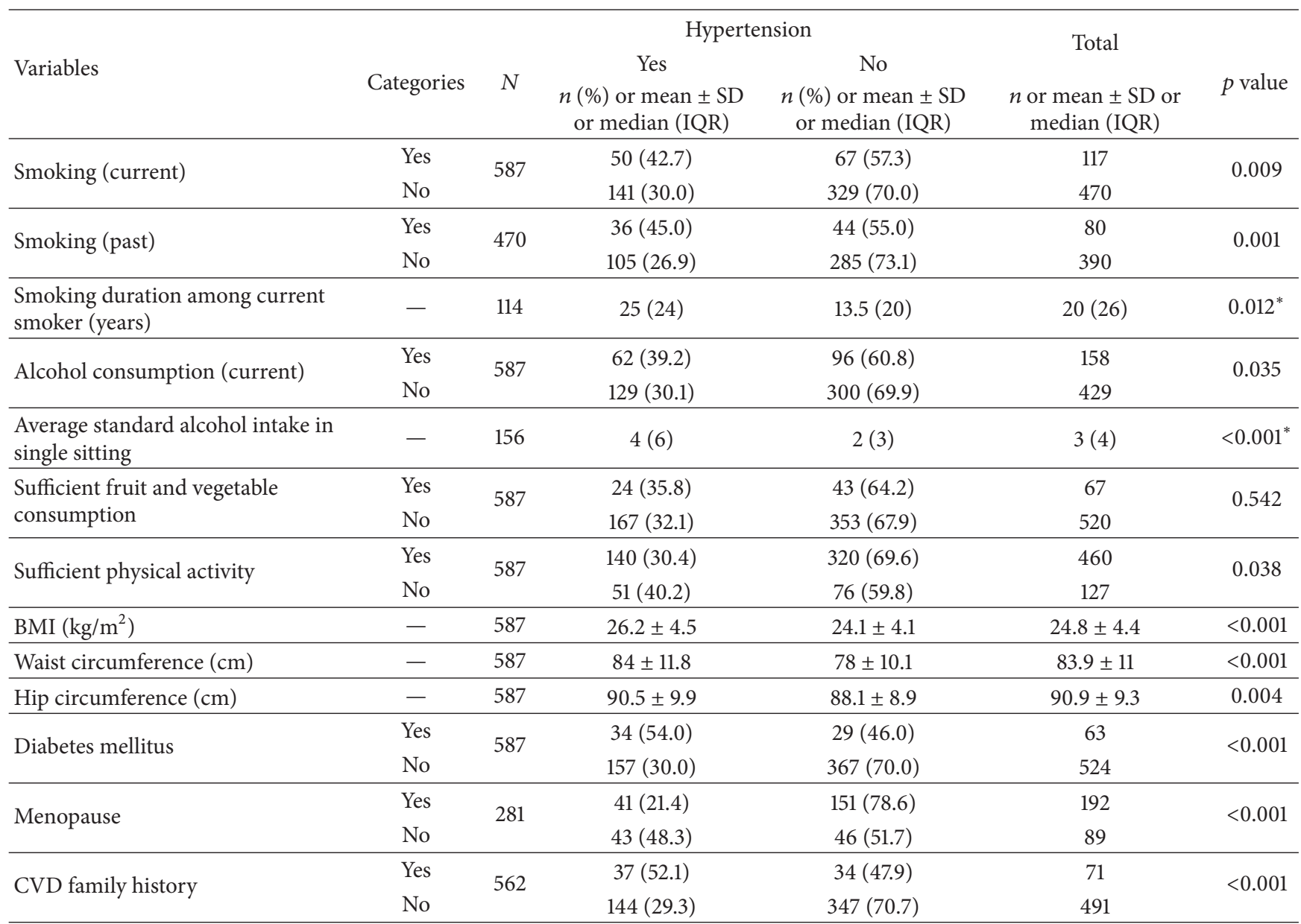

${ }^{*}$ Mann-Whitney $U$ test was used to compare nonnormally distributed data.

Note: sufficient fruit and vegetable consumption, intake of $\geq 400 \mathrm{gm}$ of fruit and vegetable per day; sufficient physical activity, $\geq 600$ METs of moderate and vigorous activity in a week; one standard drink, 10 grams of ethanol.

BMI, body mass index; CVD, cardiovascular disease.

TABLE 4: Multivariable analysis for hypertension.

\begin{tabular}{|c|c|c|c|c|c|c|}
\hline \multirow{2}{*}{ Variables } & \multirow{2}{*}{ Category } & \multirow{2}{*}{$\beta$} & \multirow{2}{*}{$p$ value } & \multirow{2}{*}{ AOR } & \multicolumn{2}{|c|}{$95 \% \mathrm{CI}$ for $\mathrm{AOR}$} \\
\hline & & & & & Lower & Upper \\
\hline Constant & & -2.220 & 0.005 & 0.109 & & \\
\hline $\operatorname{BMI}\left(\mathrm{kg} / \mathrm{m}^{2}\right)$ & & 0.127 & $<0.001$ & 1.135 & 1.084 & 1.188 \\
\hline \multirow{2}{*}{ Smoking (current) } & No & & & Reference & & \\
\hline & Yes & 0.671 & 0.005 & 1.957 & 1.219 & 3.141 \\
\hline \multirow{2}{*}{ Alcohol user (current) } & No & & & Reference & & \\
\hline & Yes & 0.473 & 0.030 & 1.605 & 1.047 & 2.460 \\
\hline \multirow{2}{*}{ Physical activity } & Sufficient & & & Reference & & \\
\hline & Nonsufficient & 0.472 & 0.040 & 1.604 & 1.022 & 2.517 \\
\hline \multirow{2}{*}{ Diabetes mellitus-II } & No & & & Reference & & \\
\hline & Yes & 0.934 & 0.001 & 2.545 & 1.454 & 4.457 \\
\hline
\end{tabular}

Note: sufficient physical activity, $\geq 600$ METs of moderate and vigorous activity in a week.

BMI, body mass index. 
differ between study settings and populations. Our study showed that smoking increased the likelihood of being hypertensive by twofold. This finding is consistent with previous studies conducted in India and China [29-31]. However, some observational studies reported smokers having a lower risk of hypertension than nonsmokers, which contrasted to our finding [32-37]. Our study also found that the median length of smoking duration was significantly higher among the hypertensive participants. Therefore, one of the reasons for the aforementioned inconsistency in findings could be the variations in frequency and total duration of smoking.

Our study found that the odds of having hypertension were increased by 1.6 times with the use of alcohol. The result was in line with the findings reported by Todkar et al. in India and Wei et al. in China [38, 39]. However, there are some studies that found protective effects of alcohol on hypertension [40, 41]. Some also failed to demonstrate any significant association between alcohol consumption and hypertension [30, 35]. These differences in findings might have occurred because of difference in amount and concentration of alcohol consumed. Sacco et al. and Kannel and Ellison concluded that protective effect of alcohol in hypertension and other cardiovascular diseases was mainly detected among the moderate alcohol users (up to two standard drinks per day). The effect was opposite among those consuming seven and more drinks per day [40, 41]. A meta-analysis of 15 randomized controlled trials observed a dose response relationship of alcohol reduction and on blood pressure [42]. This is supported by the current findings which demonstrated that the median number of standard drinks consumed was significantly higher among the hypertensive participants. Further research is required to explain the apparent bidirectional effects of alcohol intake on hypertension.

The current study revealed that one in every four participants reported being a current alcohol user. The proportion was higher than that of recent noncommunicable disease risk factor survey (17.4\%) in Nepal [25]. This may be due to a higher social acceptance of alcohol use in the study areas compared to Nepal as a whole. The high rates of alcohol consumption in this population need to be considered when implementing programs to address hypertension.

Despite the well-recognized inverse relationship between fruit and vegetable consumption and hypertension [43, 44], our study showed no association between them. A study conducted in rural Nepal also reported a similar result [26]. A more detailed food frequency questionnaire in future studies may assist in confirming these findings. However, the fluctuating pattern of fruit and vegetable consumption in Nepal due to the seasonal availability of these foods may make clarifying the association with hypertension difficult [24]. The ideal measure of Nepalese fruit and vegetable consumption warrants further discussion.

This study found that sedentary lifestyle was an issue in this study population. The proportion of participants (21.6\%) having insufficient physical activity (<600 METs/Week) was six times higher than that reported in a national survey (3.5\%) [25]. Unplanned and rapid urbanization, high population density, increased use of motorized vehicles and, modern technology could be predisposing factors for low physical activity among this population [45]. The increased risk of hypertension among study participants reporting low levels of physical activity was consistent with other studies [30, 32, 45]. These findings suggest that several cardiometabolic problems may arise in near future as the consequences of insufficient physical activity. Even though confirming the causal relationship between physical activity and cardiometabolic diseases, including hypertension, is beyond the scope of this study, several previous studies have demonstrated the association [46, 47]. Therefore, Nepal should not delay initiating interventions that improve physical activity through community-based strategies that incorporate informational, behavioral, social, policy-making, and environmental approaches [48].

Body mass index, waist circumference, and hip circumference, all measures related to overweight and obesity, were significantly higher in hypertensive participants than in normotensive participants. These findings were in line with results from previous studies conducted in Nepal [26, 28]. Like physical inactivity, obesity has also well-recognized independent relationship with a spectrum of cardiometabolic disorders including hypertension [49]. There are several mechanisms hypothesized to explain the link between obesity with hypertension $[10,11,49,50]$. It is generally thought that the accumulation of visceral and ectopic fat in a number of tissues and organs alters the metabolic and hemodynamic pathways, leading to the development of hypertension in obese people $[49,50]$. The reduction of overweight and obesity by improving nutrition and increasing regular physical activity is the best way to avoid or improve hypertension [51].

Diabetes was associated with twofold increased odds of being hypertensive. The finding was consistent with the results of the studies conducted in similar settings of Kathmandu, Nepal [52, 53], and internationally [54, 55]. Hypertension is often reported to be one of the most common comorbid conditions in those suffering from diabetes. For instance, around half of diabetic patients in Australia have hypertension [56]. Similarly, almost a quarter of hypertensive patients were found to have diabetes in China and India [57, 58]. The coexistence of hypertension and diabetes might be because of sharing common risk factors like smoking, alcohol consumption, unhealthy diets, and physical inactivity. Due to nature of this study, it is difficult to state with certainty whether diabetes led to hypertension or hypertension led to diabetes. This study only included self-reported diabetic cases, which would underestimate the rate of diabetes in the study population. Further research is required in this population to accurately estimate the impact of diabetes on hypertension.

Our study also found associations between hypertension and other recognized risk factors including menopause [5961]. Similarly, presence of cardiovascular diseases including hypertension among first-degree relatives of the participants had a significant association with hypertension among study population. The familial pattern of hypertension was well established long before [62], and it is now considered as one of the major nonmodifiable risk factors for hypertension, like age and race [63]. 
This study identifies some of the major factors associated with hypertension in people living in the outer areas of Kathmandu. Several of these factors could be targeted to improve the health of the population in these areas. One example where improvements have been made is in relation to smoking. The proportion of current smoking in our study (19.9\%) was similar to that of a national survey $(18.5 \%)$ conducted in Nepal [25]. After signing the WHO Framework Convention on Tobacco Control (WHO FCTC), Nepal is implementing tobacco control initiatives such as health warnings on tobacco products, prohibition of smoking in public places, heavy taxation of the tobacco industry, and increasing public awareness of harmful effects of tobacco. Since these initiatives have been implemented there has been a decreasing trend in prevalence of smoking in Nepal [64, 65]. The presence of large proportion of past smokers (17\%) in current study might also suggest the trend of quitting smoking in the study areas. These initiatives should also lead to an improvement in the health of people in Nepal, including a reduction in the risk of hypertension. Initiatives to improve factors like physical activity and alcohol consumption in these regions of Nepal would also be useful in reducing the risk of hypertension and improving overall health.

\section{Conclusion}

Overall, this study determined a high prevalence of hypertension in the study population. Hypertension was associated with smoking, alcohol consumption, low physical activity, obesity, and diabetes. Therefore, community-based approaches for reduction of hypertension and its risk factors are essential. Effective community-based preventive and control strategies might provide the best opportunities to avoid hypertension driven health and economic consequences in Nepal.

\section{Ethical Approval}

The study protocol was reviewed and approved by Ethical Review Board of the Nepal Health Research Council, Kathmandu. Written consent was obtained from all participants after detailed explanation of research purpose and assurance of maintaining privacy and confidentiality. Those who needed further treatment were referred to tertiary treatment centers.

\section{Competing Interests}

The authors declare that they have no competing interests.

\section{Authors' Contributions}

Raja Ram Dhungana provided concept, designed and executed the study, analyzed and interpreted the data, and prepared the first draft of the paper. Achyut Raj Pandey, Bihungum Bista, and Suira Joshi provided an input on statistical analysis, interpretation of study, and preparation of the draft. Surya Devkota contributed in study concept, design, and interpretation. All authors read and approved the final paper.

\section{Acknowledgments}

The authors want to express their gratitude and appreciation to Dr. Damien Cordery, Senior Epidemiologist, for providing the first review of the paper. They would like to thank field supervisor and data enumerator team: Dr. Savyata Panthi, Mr. Rajan Gyawali, Mr. Krishna Gyawali, Miss Santi Timalsina, Mr. Nawaraj Vetwal, Mr. BikasMaharjan, Mr. Deepen Devkota, Mr. Dependra Jung Rana, Miss Bibechana Pandey, Miss Amrita Paudel, Mr. Lokendra Karki, Mr. Santosh Singh Thapa, Miss Shila Sapkota, and Miss Jenny Roka. Also, special thanks are due to Kageshwari-Manohara and Nagarjun municipalities' members, FCHV team, and local leaders for helping in community mobilization. This study was funded by a research grant from Jayanti Memorial Trust, Kathmandu, Nepal.

\section{References}

[1] S. S. Lim, T. Vos, A. D. Flaxman et al., "A comparative risk assessment of burden of disease and injury attributable to 67 risk factors and risk factor clusters in 21 regions, 1990-2010: a systematic analysis for the Global Burden of Disease Study 2010," The Lancet, vol. 380, no. 9859, pp. 2224-2260, 2012.

[2] Global Health Observatory Data Repository, http://apps.who .int/gho/data/view.main.2540?lang=en.

[3] T. A. Gaziano, A. Bitton, S. Anand, and M. C. Weinstein, "The global cost of nonoptimal blood pressure," Journal of Hypertension, vol. 27, no. 7, pp. 1472-1477, 2009.

[4] World Health Organization, "A global brief on Hypertension, silent killer, global public health crisis. 2013," 2014, http://apps.who.int/iris/bitstream/10665/79059/1/WHO_DCO_ WHD_2013.2_eng.pdf.

[5] WHO, The World Health Report 2002: Reducing Risks, Promoting Healthy Life, World Health Organization, Geneva, Switzerland, 2002.

[6] J. A. Ambrose and R. S. Barua, "The pathophysiology of cigarette smoking and cardiovascular disease: an update," Journal of the American College of Cardiology, vol. 43, no. 10, pp. 1731-1737, 2004.

[7] L. J. Beilin and I. B. Puddey, "Alcohol and hypertension: an update," Hypertension, vol. 47, no. 6, pp. 1035-1038, 2006.

[8] H. D. Sesso, N. R. Cook, J. E. Buring, J. E. Manson, and J. M. Gaziano, "Alcohol consumption and the risk of hypertension in women and men," Hypertension, vol. 51, no. 4, pp. 1080-1087, 2008.

[9] N. R. C. Campbell, D. T. Lackland, and M. L. Niebylski, "2014 dietary salt fact sheet of the world hypertension league, international society of hypertension, pan American health organization technical advisory group on cardiovascular disease prevention through dietary salt reduction, the world health organization collaborating centre on population salt reduction, and world action on salt \& health," Journal of Clinical Hypertension, vol. 17, no. 1, pp. 7-9, 2015.

[10] L. Landsberg, "Diet, obesity and hypertension: an hypothesis involving insulin, the sympathetic nervous system, and adaptive thermogenesis," Quarterly Journal of Medicine, vol. 61, no. 236, pp. 1081-1090, 1986. 
[11] F. Abbasi, B. W. Brown Jr., C. Lamendola, T. McLaughlin, and G. M. Reaven, "Relationship between obesity, insulin resistance, and coronary heart disease risk," Journal of the American College of Cardiology, vol. 40, no. 5, pp. 937-943, 2002.

[12] K.-H. Wagner and H. Brath, "A global view on the development of non communicable diseases," Preventive Medicine, vol. 54, pp. S38-S41, 2012.

[13] A. Contractor, B. K. Sarkar, M. Arora, and K. Saluja, "Addressing cardiovascular disease burden in low and middle income countries (LMICs)," Current Cardiovascular Risk Reports, vol. 8, no. 11, pp. 1-9, 2014.

[14] E. Muzzini and G. Aparicio, Urban Growth and Spatial Transition in Nepal, The World Bank, Washington, DC, USA, 2014.

[15] Government of Nepal, National Population and Housing Census 2011, vol. 2, Central Bureau of Statistics, Kathmandu, Nepal, 2012.

[16] World Health Organization, WHO STEPS Surveillance Manual, World Health Organization, Geneva, Switzerland, 2008.

[17] The WHO STEPwise approach to chronic disease risk factor surveillance (STEPS), http://www.who.int/chp/steps/STEPS_ Instrument_v2.1.pdf.

[18] W. L. Haskell, I.-M. Lee, R. R. Pate et al., "Physical activity and public health: updated recommendation for adults from the American College of Sports Medicine and the American Heart Association," Circulation, vol. 116, no. 9, pp. 1081-1093, 2007.

[19] The 2011 Compendium of Physical Activities: Tracking Guide, https://sites.google.com/site/compendiumofphysicalactivities/ tracking-guide.

[20] Central Bureau of Statistics and World Bank, Poverty in Nepal 2010-11: Findings from NLSS-III, 2012, http://un.org.np/ data-coll/Demography-Publications/2011\%20Key\%20Findings (\%20NLSS\%20III).pdf.

[21] Ministry of Health and Population GoN and Society for Local Integrated Development Nepal (SOLID Nepal) and WHO, "WHO STEPS surveillance: non-communicable diseases risk factors survey," in Kathmandu, Ministry of Health and Population, Government of Nepal, Society for Local Integrated Development Nepal (SOLID Nepal) and WHO, 2008.

[22] J. N. Hall, S. Moore, S. B. Harper, and J. W. Lynch, "Global variability in fruit and vegetable consumption," American Journal of Preventive Medicine, vol. 36, no. 5, pp. 402-409.e405, 2009.

[23] C. Lenfant, A. V. Chobanian, D. W. Jones, and E. J. Roccella, "Seventh report of the joint national committee on the prevention, detection, evaluation, and treatment of high blood pressure (JNC 7): resetting the hypertension sails," Hypertension, vol. 41, no. 6, pp. 1178-1179, 2003.

[24] S. K. Wanga and S. Lemeshow, Sample Size Determination in Health Studies. A Practical Manual Ginebra, World Health Organization, Geneva, Switzerland, 1991.

[25] K. K. Aryal, S. Neupane, S. Mehata et al., Non Communicable Disease Risk Factors: STEPS Survey Nepal 2013, Nepal Health Research Council, 2013.

[26] R. R. Dhungana, S. Devkota, M. K. Khanal et al., "Prevalence of cardiovascular health risk behaviors in a remote rural community of Sindhuli district, Nepal," BMC Cardiovascular Disorders, vol. 14, article 92, 2014.

[27] D. Sharma, M. Bkc, S. Rajbhandari et al., "Study of prevalence, awareness, and control of hypertension in a suburban area of Kathmandu, Nepal," Indian Heart Journal, vol. 58, no. 1, pp. 3437, 2005.
[28] A. Vaidya, R. P. Pathak, and M. R. Pandey, "Prevalence of hypertension in Nepalese community triples in 25 years: a repeat cross-sectional study in rural Kathmandu," Indian Heart Journal, vol. 64, no. 2, pp. 128-131, 2012.

[29] R. B. Singh, J. Fedacko, D. Pella et al., "Prevalence and risk factors for prehypertension and hypertension in five Indian cities," Acta Cardiologica, vol. 66, no. 1, pp. 29-37, 2011.

[30] C. S. Shanthirani, R. Pradeepa, R. Deepa, G. Premalatha, R. Saroja, and V. Mohan, "Prevalence and risk factors of hypertension in a selected South Indian population-the Chennai Urban Population Study," Journal of Association of Physicians of India, vol. 51, pp. 20-27, 2003.

[31] V. Mohan, M. Deepa, S. Farooq, M. Datta, and R. Deepa, "Prevalence, awareness and control of hypertension in Chennaithe Chennai Urban Rural Epidemiology study (CURES-52)," Journal of Association of Physicians of India, vol. 55, pp. 326-332, 2007.

[32] P. Malhotra, S. Kumari, R. Kumar, S. Jain, and B. K. Sharma, "Prevalence and determinants of hypertension in an unindustrialised rural population of North India," Journal of Human Hypertension, vol. 13, no. 7, pp. 467-472, 1999.

[33] S. Panesar, S. Chaturvedi, N. Saini, R. Avasthi, and A. Singh, "Prevalence and predictors of hypertension among residents aged 20-59 years of a slum-resettlement colony in Delhi, India," WHO South-East Asia Journal of Public Health, vol. 2, no. 2, pp. 83-87, 2013.

[34] J.-C. Katte, A. Dzudie, E. Sobngwi et al., "Coincidence of diabetes mellitus and hypertension in a semi-urban Cameroonian population: a cross-sectional study," BMC Public Health, vol. 14, article 696, 2014.

[35] J. Chataut, R. K. Adhikari, and S. Np, “The prevalence of and risk factors for hypertension in adults living in central development region of Nepal," Kathmandu University Medical Journal, vol. 9, no. 33, pp. 13-18, 2011.

[36] Z. Sun, L. Zheng, R. Detrano et al., "Incidence and predictors of hypertension among rural Chinese adults: results from Liaoning Province," Annals of Family Medicine, vol. 8, no. 1, pp. 19-24, 2010.

[37] G. D. Friedman, A. L. Klatsky, and A. B. Slegelaub, "Alcohol, tobacco, and hypertension," Hypertension, vol. 4, no. 5, part 2, pp. Iiil43-Iiil50, 1982.

[38] S. S. Todkar, V. V. Gujarathi, and V. S. Tapare, "Period prevalence and sociodemographic factors of hypertension in rural Maharashtra: a cross-sectional study," Indian Journal of Community Medicine, vol. 34, no. 3, pp. 183-187, 2009.

[39] Q. Wei, J. Sun, J. Huang et al., "Prevalence of hypertension and associated risk factors in Dehui City of Jilin Province in China," Journal of Human Hypertension, vol. 29, no. 1, pp. 64-68, 2015.

[40] R. L. Sacco, M. Elkind, B. Boden-Albala et al., "The protective effect of moderate alcohol consumption on ischemic stroke," The Journal of the American Medical Association, vol. 281, no. 1, pp. 53-60, 1999.

[41] W. B. Kannel and R. C. Ellison, "Alcohol and coronary heart disease: the evidence for a protective effect," Clinica Chimica Acta, vol. 246, no. 1-2, pp. 59-76, 1996.

[42] X. Xin, J. He, M. G. Frontini, L. G. Ogden, O. I. Motsamai, and P. K. Whelton, "Effects of alcohol reduction on blood pressure: a meta-analysis of randomized controlled trials," Hypertension, vol. 38, no. 5, pp. 1112-1117, 2001.

[43] J. M. Nuñez-Cordoba, A. Alonso, J. J. Beunza, S. Palma, E. Gomez-Gracia, and M. A. Martinez-Gonzalez, "Role of vegetables and fruits in Mediterranean diets to prevent hypertension," 
European Journal of Clinical Nutrition, vol. 63, no. 5, pp. 605612, 2009.

[44] M. T. Utsugi, T. Ohkubo, M. Kikuya et al., "Fruit and vegetable consumption and the risk of hypertension determined by self measurement of blood pressure at home: the Ohasama study," Hypertension Research, vol. 31, no. 7, pp. 1435-1443, 2008.

[45] A. Vaidya and A. Krettek, "Physical activity level and its sociodemographic correlates in a peri-urban Nepalese population: a cross-sectional study from the Jhaukhel-Duwakot health demographic surveillance site," International Journal of Behavioral Nutrition and Physical Activity, vol. 11, no. 1, article 39, 2014.

[46] B. Arroll and R. Beaglehole, "Does physical activity lower blood pressure: a critical review of the clinical trials," Journal of Clinical Epidemiology, vol. 45, no. 5, pp. 439-447, 1992.

[47] S. P. Whelton, A. Chin, X. Xin, and J. He, "Effect of aerobic exercise on blood pressure: a meta-analysis of randomized, controlled trials," Annals of Internal Medicine, vol. 136, no. 7, pp. 493-503, 2002.

[48] C. Blanchard, T. Shilton, and F. Bull, "Global Advocacy for Physical Activity (GAPA): global leadership towards a raised profile," Global Health Promotion, vol. 20, no. 4, supplement, pp. 113-121, 2013.

[49] K. P. Davy and J. E. Halle, "Obesity and hypertension: two epidemics or one?" American Journal of Physiology-Regulatory Integrative and Comparative Physiology, vol. 286, no. 5, pp. R803-R813, 2004.

[50] P. Poirier, T. D. Giles, G. A. Bray et al., "Obesity and cardiovascular disease: pathophysiology, evaluation, and effect of weight loss," Arteriosclerosis, Thrombosis, and Vascular Biology, vol. 26, no. 5, pp. 968-976, 2006.

[51] B. H. Goodpaster, J. P. DeLany, A. D. Otto et al., "Effects of diet and physical activity interventions on weight loss and cardiometabolic risk factors in severely obese adults: a randomized trial," The Journal of the American Medical Association, vol. 304, no. 16, pp. 1795-1802, 2010.

[52] M. R. Chhetri and R. S. Chapman, "Prevalence and determinants of diabetes among the elderly population in the Kathmandu Valley of Nepal," Nepal Medical College Journal, vol. 11, no. 1, pp. 34-38, 2009.

[53] U. K. Shrestha, D. L. Singh, and M. D. Bhattarai, "The prevalence of hypertension and diabetes defined by fasting and 2-h plasma glucose criteria in urban Nepal," Diabetic Medicine, vol. 23, no. 10, pp. 1130-1135, 2006.

[54] A. Awoke, T. Awoke, S. Alemu, and B. Megabiaw, "Prevalence and associated factors of hypertension among adults in Gondar, Northwest Ethiopia: a community based cross-sectional study," BMC Cardiovascular Disorders, vol. 12, article 113, 2012.

[55] Y. Gao, G. Chen, H. Tian et al., "Prevalence of hypertension in China: a cross-sectional study," PLoS ONE, vol. 8, no. 6, Article ID e65938, 2013.

[56] G. E. Caughey, A. I. Vitry, A. L. Gilbert, and E. E. Roughead, "Prevalence of comorbidity of chronic diseases in Australia," BMC Public Health, vol. 8, article 221, 2008.

[57] J. Liu, R. Wang, K. Desai, and L. Wu, "Upregulation of aldolase $\mathrm{B}$ and overproduction of methylglyoxal in vascular tissues from rats with metabolic syndrome," Cardiovascular Research, vol. 92, no. 3, pp. 494-503, 2011.

[58] K. Venugopal and M. Z. Mohammed, "Prevalence of hypertension in type-2 diabetes mellitus," CHRISMED Journal of Health and Research, vol. 1, no. 4, pp. 223-227, 2014.
[59] J. A. Staessen, G. Ginocchio, L. Thijs, and R. Fagard, "Conventional and ambulatory blood pressure and menopause in a prospective population study," Journal of Human Hypertension, vol. 11, no. 8, pp. 507-514, 1997.

[60] A. S. Sapkota, A. Sapkota, K. Acharya, M. Raut, and B. Jha, "Study of metabolic syndrome in postmenopausal women," Annals of Clinical Chemistry and Laboratory Medicine, vol. 1, no. 1, pp. 6-11, 2015.

[61] M. Coylewright, J. F. Reckelhoff, and P. Ouyang, "Menopause and hypertension: an age-old debate," Hypertension, vol. 51, no. 4, pp. 952-959, 2008.

[62] C. B. Thomas, "Familial patterns in hypertension and coronary heart disease," Circulation, vol. 20, no. 1, pp. 25-29, 1959.

[63] K. Bell, J. Twiggs, and B. R. Olin, Hypertension: The Silent Killer: Updated JNC-8 Guideline Recommendations, Alabama Pharmacy Association, Montgomery, Ala, USA, 2015.

[64] MOHP, New ERA, and ICF International, "Nepal Demographic and Health Survey," in Kathmandu, MOHP, New ERA, ICF International, 2006.

[65] MOHP, New ERA, and ICF International, "Nepal demographic and health survey," in Nepal: Demographic and Health Survey, MOHP, New ERA, ICF International, 2011. 


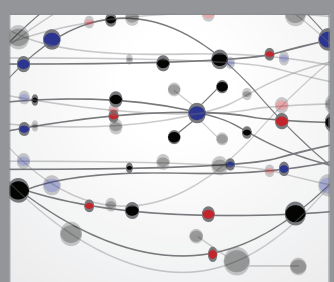

The Scientific World Journal
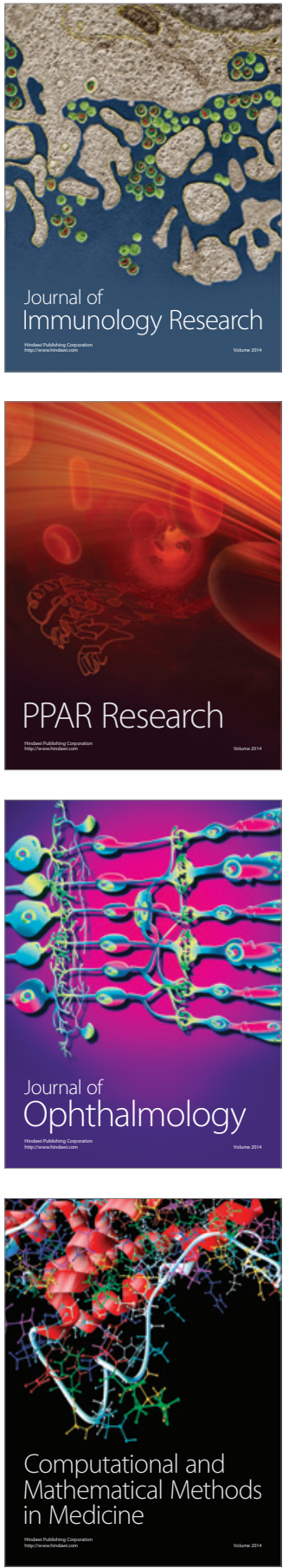

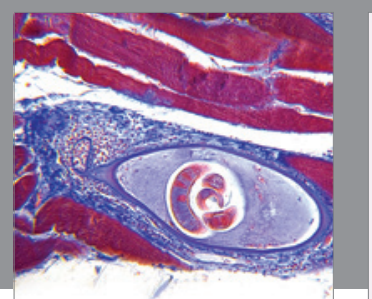

Gastroenterology Research and Practice

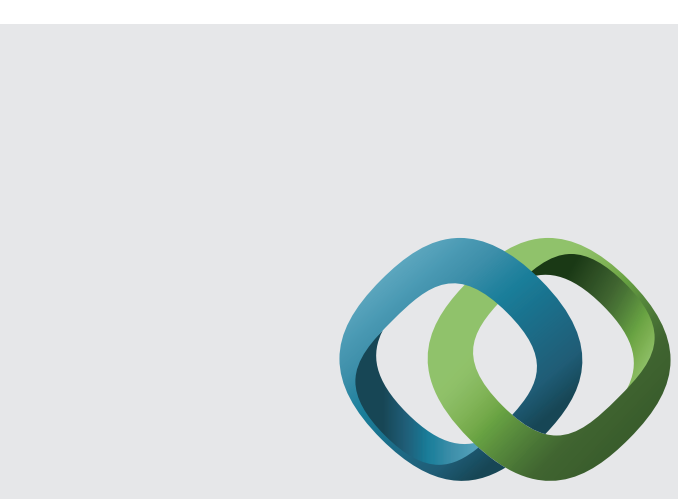

\section{Hindawi}

Submit your manuscripts at

http://www.hindawi.com
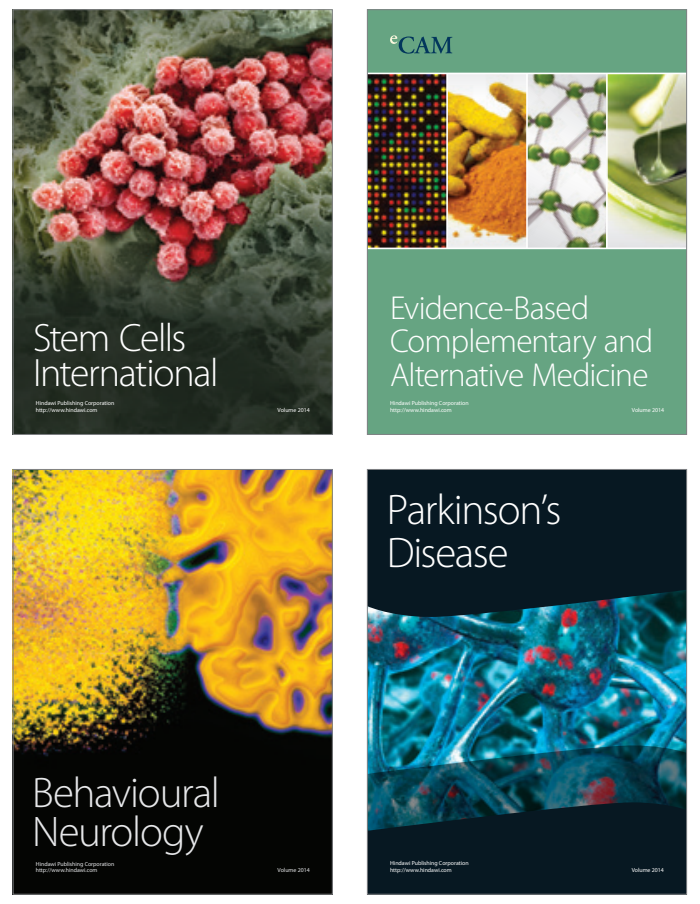
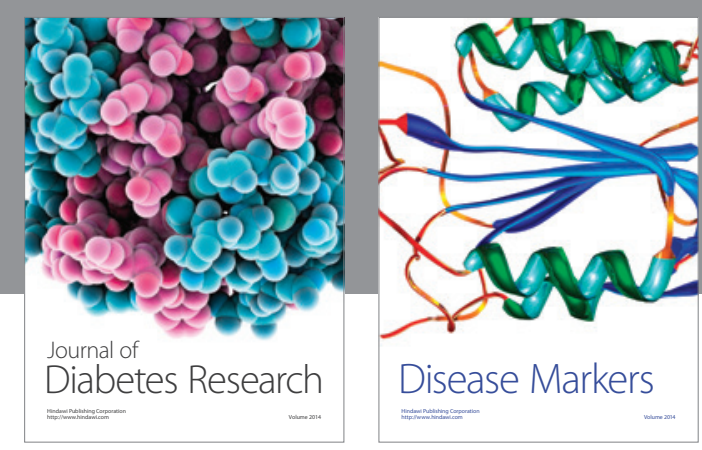

Disease Markers
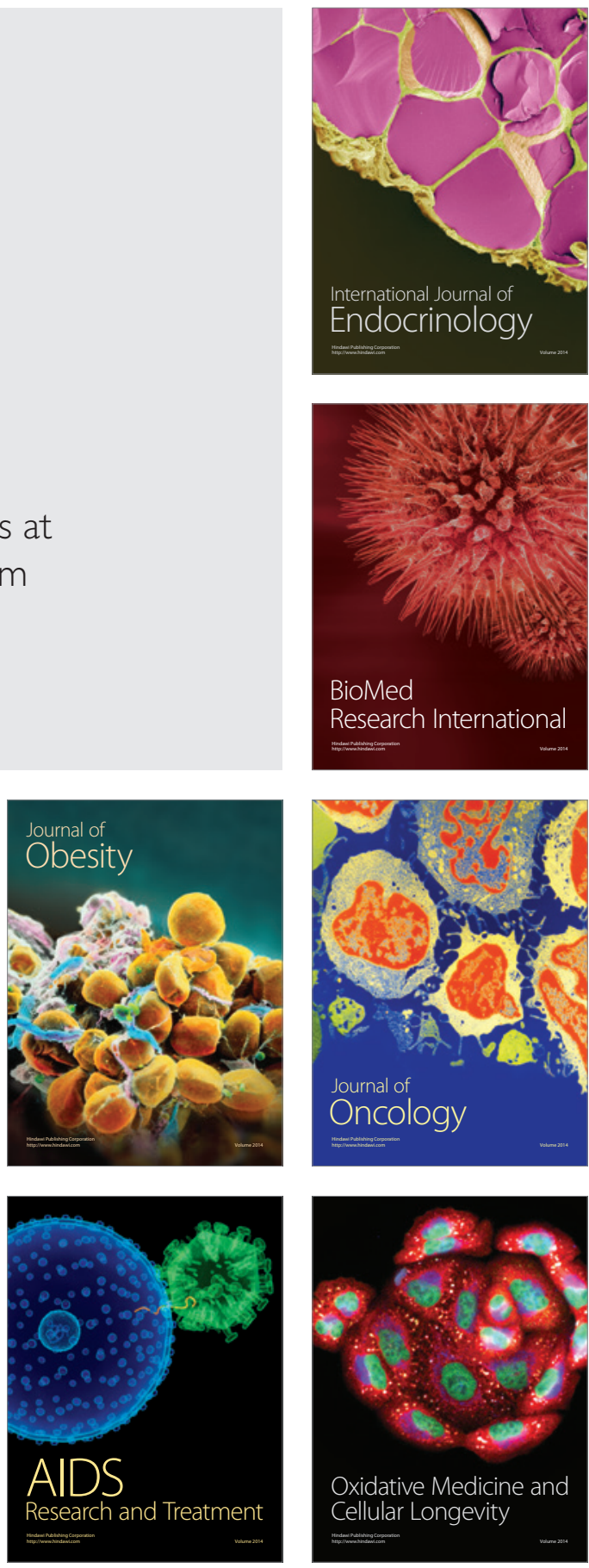